\title{
Comparison of health outcomes among affiliated and lay disaster volunteers enrolled in the World Trade Center Health Registry
}

\author{
Indira Debchoudhury a,*, Alice E. Welch ${ }^{a}$, Monique A. Fairclough ${ }^{a}$, James E. Cone a , Robert M. Brackbill a, \\ Steven D. Stellman ${ }^{\mathrm{a}, \mathrm{b}}$, Mark R. Farfel ${ }^{\mathrm{a}}$ \\ ${ }^{a}$ New York City Department of Health and Mental Hygiene, World Trade Center Health Registry, 2 Gotham Center, 42-09 28th Street, 7th Floor, Queens, NY 11101, USA \\ ${ }^{\mathrm{b}}$ Department of Epidemiology, Mailman School of Public Health, Columbia University, New York, NY, USA
}

\section{A R T I C L E I N F O}

Available online 10 September 2011

\section{Keywords:}

Volunteers

Affiliated Volunteers

Lay Volunteers

Rescue and Recovery

September 11th

Disaster

Mental Health

Physical Health

World Trade Center

\begin{abstract}
A B S T R A C T
Background. Volunteers (non-professional rescue/recovery workers) are universally present at manmade and natural disasters and share experiences and exposures with victims. Little is known of their disaster-related health outcomes.

Methods. We studied 4974 adult volunteers who completed the World Trade Center Health Registry 2006-07 survey to examine associations between volunteer type (affiliated vs. lay) and probable posttraumatic stress disorder (PTSD); new or worsening respiratory symptoms; post-9/11 first diagnosis of anxiety disorder, depression, and/or PTSD; and asthma or reactive airway dysfunction syndrome (RADS). Affiliated volunteers reported membership in a recognized organization. Lay volunteers reported no organizational af filiation and occupations unrelated to rescue/recovery work. Adjusted odds ratios $\left(\mathrm{OR}_{\mathrm{adj}}\right)$ were calculated using multinomial regression.

Results. Lay volunteers were more likely than affiliated volunteers to have been present in lower Manhattan, experience the dust cloud, horrific events and injury on 9/11 and subsequently to report unmet healthcare needs. They had greater odds of early post-9/11 mental health diagnosis ( $\left.\mathrm{OR}_{\text {adj }} 1.6 ; 95 \% \mathrm{CI}: 1.4-2.0\right)$ and asthma/RADS (1.8; 1.2-2.7), chronic PTSD (2.2; 1.7-2.8), late-onset PTSD (1.9; $1.5-2.5)$, and new or worsening lower respiratory symptoms $(2.0 ; 1.8-2.4)$.

Conclusions. Lay volunteers' poorer health outcomes reflect earlier, more intense exposure to and lack of protection from physical and psychological hazards. There is a need to limit volunteers' exposures during and after disasters, as well as to provide timely screening and health care post-disaster.

(c) 2011 Elsevier Inc. All rights reserved.
\end{abstract}

\section{Introduction}

Volunteers are a universal feature of man-made and natural disasters serving as one of the main sources of outside support in postdisaster recovery work (Thormar, et al., 2010). In the last decade, volunteers have played a key role in recovery and relief efforts after the oil spill in the Gulf of Mexico (2010), the Haitian earthquake (2010), Hurricane Katrina (2005), the London transit bombings (2005), and the Indian Ocean earthquake and tsunami (2004). Volunteer participation is often necessary and unavoidable due to the magnitude and impact of such events (Thormar, et al., 2010).

\footnotetext{
* Corresponding author at: New York City Department of Health and Mental Hygiene, World Trade Center Health Registry, 2 Gotham Center, 42-09 28th Street, 7th Floor, Queens, NY 11101, USA. Fax: +1 2127884127.

E-mail addresses: idebchou@health.nyc.gov (I. Debchoudhury),

awelch1@health.nyc.gov (A.E. Welch), mfairclo@health.nyc.gov (M.A. Fairclough), jcone@health.nyc.gov (J.E. Cone), rbrackbi@health.nyc.gov (R.M. Brackbill), sstellma@health.nyc.gov (S.D. Stellman),mfarfel@health.nyc.gov (M.R. Farfel).
}

On September 11, 2001, two airplanes crashed into the Twin Towers of the World Trade Center (WTC), causing their collapse and extensive damage to numerous other buildings. Approximately 2800 people lost their lives (Farfel, et al., 2008). Subsequent recovery and relief efforts included paid and volunteer professional rescue/ recovery workers (RRW) (fire, police or other emergency personnel), volunteers affiliated with relief organizations and lay volunteers (i.e., not affiliated with a recognized response organization) (American Red Cross, 2002, Steffen and Fothergill, 2009, Tierney, et al., 2001). The WTC disaster exposed an estimated 409,000 individuals to potentially hazardous chemicals, environmental toxins and psychological stressors that are risk factors for asthma and posttraumatic stress disorder (PTSD) (Landrigan, et al., 2004, Murphy, et al., 2007). A recent review found that all WTC disaster workers including volunteers faced an increased risk of mental health sequelae as a consequence of their intense disaster exposures (Bills, et al., 2008). Findings from the 2003-04 WTC Health Registry (Registry) survey demonstrate that RRW in occupations less prepared for the type of work performed at WTC sites were more likely to develop PTSD (Perrin, et al., 2007). 
To build upon previous Registry findings by expanding the range of post-disaster outcomes, Registry data were used to compare mental and physical health outcomes and health care utilization among affiliated and lay volunteers. We hypothesized that lay volunteers would be more likely than affiliated volunteers to experience longterm adverse mental and physical health outcomes due to earlier arrival at WTC sites and more intense exposure to a multitude of hazards, as well as a lack of training, prior disaster experience, or insufficient post-disaster support. We also predicted they would be more likely to report unmet health care needs and less utilization of post-9/11 monitoring and treatment programs.

\section{Methods}

The Registry, created in 2002 by the NYC Department of Health and Mental Hygiene (NYCDOHMH) in collaboration with the Agency for Toxic Substances and Disease Registry, prospectively follows 71,437 individuals highly exposed to the WTC disaster and belonging to one or more eligibility groups: RRW and volunteers, lower Manhattan residents, area workers, passers-by, and school children and staff. The protocol was approved by the institutional review boards of the Centers for Disease Control and Prevention and NYCDOHMH.

List-identified enrollees were recruited from lists of potentially eligible individuals from governmental agencies, organizations, and employers, Self-identified enrollees contacted the Registry via phone or pre-registered on a website. The 2003-04 Wave 1 survey (W1) included 68,802 adults (Farfel, et al., 2008). The 2006-07 Wave 2 (W2) survey updated the health status of 46,322 of the original adult enrollees (68\% response rate) (Brackbill, et al., 2009). Registry methods are described in detail elsewhere (Brackbill, et al., 2009, Farfel, et al., 2008, Perrin, et al., 2007).

The present analysis focuses on 4974 enrollees who completed W1 and W2 surveys, were aged 18 years or older on $9 / 11$, and reported volunteering in rescue/recovery activities between 09/11/01 and 06/30/02. Enrollees identifying as professional RRW, whether paid or unpaid for their services, were not considered volunteers for this analysis. Volunteer status was categorized as affiliated or lay based on the W1 question, "What organization did you work for at the WTC site?" Affiliated volunteers reported membership in recognized organizations (e.g., American Red Cross). Lay volunteers reported no organizational affiliation and occupations unrelated to rescue and recovery work. Lay volunteers included members of church groups or community organizations and individuals present in the area immediately following the attack. The W2 response rates for affiliated and lay volunteers were $67.7 \%$ and $67.8 \%$ respectively. From 9/11/01 to 9/14/01 lower Manhattan south of 14th street was considered a restricted zone, open only to credentialed emergency management and rescue personnel (Lorber, et al., 2007). Lay volunteers may have subsequently joined a professional organization to continue volunteering. After October 2001, only Ground Zero was restricted (Lorber, et al., 2007). Students and school staff who worked as volunteers were excluded due to small numbers.

We included as categorical variables: recruitment source (list- vs. selfidentified), gender, eligibility category (worker-only vs. multiple eligibility groups), age group, race/ethnicity, education, 2002 household income, employment status, New York City residency, and state of residence on 9/11.

We assessed exposures and experiences previously shown to be associated with increased risk of adverse mental and physical health outcomes. Presence on 9/11 was defined as meeting at least one of the following criteria: being south of Chambers Street between the first plane's impact and noon, being caught in the dust cloud, witnessing horrific events, sustaining an injury, or beginning work on the pile (the construction/restricted zone composed of rubble and remains from the collapse) on 9/11. Dust cloud exposure was classified as intense, some, or none (Brackbill, et al., 2009). Witnessing horrific events was assessed as having seen at least one of the following: an airplane hitting the WTC, people falling or jumping from the Towers, buildings collapsing, people running from a cloud or smoke, and people injured or killed. Injuries sustained on 9/11 included burns, cuts/abrasions/puncture wounds, sprain/strain, fractured/dislocated bones and head injury. Bereavement was defined as knowing anyone who lost his/her life on 9/11. Timing of volunteer work was classified by the first date enrollees worked at any WTC site and time spent at all sites combined. Because 9/11-related experiences were highly correlated with volunteer status, they were not controlled for in the data analyses.
A self-reported professional post-9/11 mental health diagnosis of depression, PTSD, and/or anxiety disorder for the first time after 9/11/01 was classified as early if diagnosed prior to $12 / 31 / 03$ and late if diagnosed between 01/01/04 and 12/31/07. Date of diagnosis reflects time of presentation for care, not disease onset. Probable PTSD was defined as a score of 44 or greater on the stressor-specific PTSD Checklist-Civilian Version and categorized into four groups: chronic (W1+ (present at W1), W2+ (present at W2)), late onset (W1- (absent at W1), W2+), resolved (W1+, W2- (absent at W2)) or no PTSD (W1-, W2-) (American Psychiatric Association, 1994, Blanchard, et al., 1996, Dobie, et al., 2002, Koenen, et al., 2003, Perrin, et al., 2007, Ruggiero, et al., 2003).

New or worsening lower respiratory symptoms (LRS) since 9/11 were defined as having at least one of these symptoms at W1 that began or got worse after 9/11: wheezing, shortness of breath and/or persistent cough. Early post9/11 asthma was defined as asthma or reactive airway dysfunction syndrome (RADS) diagnosed between 9/11/01 and 12/31/03 and late if diagnosed between 01/01/04 and 12/31/07.

Enrollees were asked at W2 if they had any unmet health care needs. Those answering affirmatively were asked if they were unable to get care for a problem related to 9/11. All were asked whether they had received any services from a list of established post-disaster medical monitoring and treatment programs.

Analyses were conducted using SAS Version 9.1 (SAS, 2005). Bivariate analyses tested differences between affiliated and lay volunteers using chisquare. Multinomial logistic analyses were performed for four outcomes: post-9/11 mental health diagnosis (early, late vs. no post-9/11), probable PTSD (chronic, late onset, resolved vs. no PTSD), new or worsening respiratory symptoms since $9 / 11$, and post-9/11 asthma/RADS (early, late vs. none). Volunteer status (with affiliated volunteers as the reference group) was the primary predictor variable for all models. Crude and adjusted odds ratios and 95\% confidence intervals $(\mathrm{CI})$ are reported. Adjustment variables were recruitment source, gender, age on 9/11, race/ethnicity, and education.

\section{Results}

Volunteer groups differed significantly on all sociodemographic characteristics except education (Table 1). Affiliated volunteers were predominately list-identified, female, members of only one eligibility group, ages 45-64 years and non-Hispanic white. The largest proportion reported a 2002 household income of \$25,000-49,999. Lay volunteers were predominantly self-identified, male, members of more than one eligibility group, ages 25-44, and non-Hispanic white. The largest proportion reported a 2002 household income of $\$ 75,000-149,999$. Lay volunteers were more likely to have known someone who lost their life on $9 / 11$ and to have lived in NYC or New York State (NYS) on 9/11.

Lay volunteers had a wider range of exposures and experiences than affiliated volunteers (Table 2 ). A substantially greater proportion of lay volunteers were present on $9 / 11$ (77.3\% vs. $25.7 \%)$, thereby at greater risk for acute exposures, such as: intense dust cloud exposure, witnessing horrific events and sustaining an injury on 9/11 than affiliated volunteers. More lay volunteers began work on 9/11 (29.7\%) and worked seven days or less (74.1\%) than affiliated volunteers. Almost half (48.7\%) of affiliated volunteers arrived between 9/18/2001 and $12 / 31 / 2001$, and the majority worked more than seven days (54.0\%).

Compared to affiliated volunteers, lay volunteers were significantly more likely to have received a post-9/11 mental health diagnosis ( $30.9 \%$ vs. $18.6 \%$ ), have probable PTSD at W1 or W2 $34.0 \%$ vs. $13.3 \%$ ), and report new or worsening LRS since $9 / 11$ (63.5\% vs. $34.9 \%$ ) as well as post $9 / 11$ asthma/RADS ( $8.5 \%$ vs. $4.3 \%$ ) (Table 3 ). Table 4.1 shows the crude and adjusted odds ratios for mental health outcomes. The odds of having an early post-9/11 mental health diagnosis was 1.6 times (95\% CI: 1.4-2.0) greater among lay than affiliated volunteers. Lay volunteers were 2.2 times (95\% CI: 1.7-2.8) more likely to have chronic probable PTSD, 1.9 times (95\% CI: $1.5-2.5$ ) more likely to have late-onset probable PTSD and 1.7 times (95\% CI: $1.2-$ 2.6) more likely to have resolved probable PTSD than affiliated 
Table 1

Demographic characteristics of volunteers enrolled in the World Trade Center Health Registry, 2006-07. N=4974.

\begin{tabular}{|c|c|c|c|}
\hline & $\begin{array}{l}\text { Affiliated } \\
\text { volunteers } \\
(n=3702)\end{array}$ & $\begin{array}{l}\text { Lay } \\
\text { volunteers } \\
(\mathrm{n}=1272)\end{array}$ & P-value \\
\hline & $\mathrm{n}(\%)$ & $\mathrm{n}(\%)$ & \\
\hline \multicolumn{4}{|l|}{ Recruitment source } \\
\hline List & $2344(63.3)$ & $268(21.1)$ & \multirow[t]{2}{*}{$<0.0001$} \\
\hline Self & $1358(36.7)$ & 1004 (78.9) & \\
\hline \multicolumn{4}{|l|}{ Gender } \\
\hline Male & $1728(46.7)$ & $869(68.3)$ & \multirow[t]{2}{*}{$<0.0001$} \\
\hline Female & $1974(53.3)$ & 403 (31.7) & \\
\hline \multicolumn{4}{|l|}{ Eligibility category $^{\mathrm{a}}$} \\
\hline Workers only & $3190(86.2)$ & $633(49.8)$ & \multirow[t]{2}{*}{$<0.0001$} \\
\hline Multiple eligibility & $512(13.8)$ & $639(50.2)$ & \\
\hline \multicolumn{4}{|l|}{ Age group (years) on $9 / 11$} \\
\hline $18-24$ & $279(7.6)$ & $86(6.8)$ & \multirow[t]{4}{*}{$<0.0001$} \\
\hline $25-44$ & $1482(40.2)$ & $758(59.7)$ & \\
\hline $45-64$ & $1640(44.5)$ & $397(31.3)$ & \\
\hline $65+$ & $287(7.8)$ & $28(2.2)$ & \\
\hline \multicolumn{4}{|l|}{ Race/ethnicity } \\
\hline White (non-Hispanic) & $3185(86.0)$ & $972(76.4)$ & \multirow[t]{5}{*}{$<0.0001$} \\
\hline $\begin{array}{l}\text { Black or African American (non- } \\
\text { Hispanic) }\end{array}$ & $106(2.9)$ & $63(5.0)$ & \\
\hline Hispanic or Latino (any race) & $231(6.2)$ & $141(11.1)$ & \\
\hline Asian & $68(1.8)$ & $51(4.0)$ & \\
\hline Other & $112(3.0)$ & $45(3.5)$ & \\
\hline \multicolumn{4}{|l|}{ Education } \\
\hline Less than 11 th Grade & $69(1.9)$ & $33(2.6)$ & \multirow[t]{5}{*}{ N.S ${ }^{b}$} \\
\hline $\begin{array}{l}\text { Grade } 12 \text { or GED } \\
\text { (high school graduate) }\end{array}$ & $555(15.1)$ & $212(16.8)$ & \\
\hline Some college & 879 (23.9) & $309(24.5)$ & \\
\hline College graduate & $1208(32.8)$ & $408(32.3)$ & \\
\hline Postgraduate degree & $974(26.4)$ & $301(23.8)$ & \\
\hline \multicolumn{4}{|l|}{$\begin{array}{l}\text { Household income in } 2002 \text { (before } \\
\text { taxes) }\end{array}$} \\
\hline$<\$ 25,000$ & $494(14.9)$ & $165(14.4)$ & \multirow[t]{5}{*}{$<0.0001$} \\
\hline$\$ 25,000$ to $<\$ 50,000$ & $969(29.2)$ & $222(19.4)$ & \\
\hline$\$ 50,000$ to $<\$ 75,000$ & $746(22.5)$ & $231(20.2)$ & \\
\hline$\$ 75,000$ to $<\$ 150,000$ & $863(26.0)$ & $384(33.5)$ & \\
\hline$\$ 150,000+$ & $244(7.4)$ & $143(12.5)$ & \\
\hline \multicolumn{4}{|l|}{ Employment status on $9 / 11$} \\
\hline Employed & 2941 (79.7) & 1136 (89.7) & $<0.0001$ \\
\hline \multicolumn{4}{|l|}{ New York City residents on 9/1 } \\
\hline Yes & $1043(28.2)$ & $809(63.6)$ & $<0.0001$ \\
\hline \multicolumn{4}{|l|}{ State lived in on $9 / 11$} \\
\hline New York & $1393(37.6)$ & $987(77.6)$ & \multirow[t]{6}{*}{$<0.0001$} \\
\hline New Jersey & $216(5.8)$ & $153(12.0)$ & \\
\hline Pennsylvania & $177(4.8)$ & $14(1.1)$ & \\
\hline California & $197(5.3)$ & $9(0.7)$ & \\
\hline Connecticut & $71(1.9)$ & $22(1.7)$ & \\
\hline Other & $1648(44.5)$ & $87(6.8)$ & \\
\hline
\end{tabular}

${ }^{a}$ Volunteers were classified as a worker only (rescue/recovery worker) or multiple eligibility (rescue/recovery worker and at least one of the following: residents, area workers, passers-by).

b N.S equals not significant.

volunteers. Table 4.2 shows the crude and adjusted odds ratios for physical health outcomes. Lay volunteers were 2.0 times more likely (95\% CI: 1.8-2.4) to report new or worsening LRS. The odds of early post-9/11 asthma/RADS were 1.8 times (95\% CI: $1.2-2.7$ ) greater among lay volunteers.

\section{Discussion}

After 9/11, thousands of people converged on the area to volunteer for recovery and relief efforts. Experiences after the disaster had a substantial impact on their long-term mental and physical health. Lay volunteers had a higher prevalence of adverse mental and physical health conditions than affiliated volunteers and both groups had a higher prevalence than the general population (Brackbill, et al., 2009). Lay volunteers were more likely to belong to more than one eligibility group and to be NYC residents. It seems evident that most were in the area
Table 2

Exposures and experiences of volunteers enrolled in the World Trade Center Health Registry, 2006-07. N=4974.

\begin{tabular}{|c|c|c|c|}
\hline & \multirow{2}{*}{$\begin{array}{l}\text { Affiliated } \\
\text { volunteers } \\
(\mathrm{n}=3702)\end{array}$} & \multirow{2}{*}{$\begin{array}{l}\text { Lay } \\
\text { volunteers } \\
(\mathrm{n}=1272) \\
\mathrm{n}(\%)\end{array}$} & \multirow[t]{2}{*}{ P-value } \\
\hline & & & \\
\hline \multicolumn{4}{|l|}{ Present on 9/11 } \\
\hline Yes & $952(25.7)$ & $983(77.3)$ & \multirow[t]{2}{*}{$<0.0001$} \\
\hline No & $2750(74.3)$ & $289(22.7)$ & \\
\hline \multicolumn{4}{|c|}{ Caught in dust cloud that resulted from the collapse of the Towers on $9 / 11^{\mathrm{b}}$} \\
\hline Intense & $259(28.1)$ & $397(42.3)$ & \multirow[t]{3}{*}{$<0.0001$} \\
\hline Some & $159(17.3)$ & $156(16.6)$ & \\
\hline None & $503(54.6)$ & $386(41.1)$ & \\
\hline \multicolumn{4}{|l|}{ Witnessed horrific events ${ }^{b}$} \\
\hline 5 horrific events witnessed & $122(13.0)$ & $166(17.2)$ & \multirow{6}{*}{$<0.0001^{\mathrm{a}}$} \\
\hline 4 horrific events witnessed & $123(13.1)$ & $171(17.7)$ & \\
\hline 3 horrific events witnessed & $156(16.6)$ & $183(19.0)$ & \\
\hline 2 horrific events witnessed & $173(18.4)$ & $182(18.9)$ & \\
\hline 1 horrific event witnessed & $230(24.5)$ & $175(18.1)$ & \\
\hline 0 horrific events witnessed & $135(14.4)$ & $88(9.1)$ & \\
\hline \multicolumn{4}{|l|}{ Type of horrific events witnessed ${ }^{b, c}$} \\
\hline Airplane hitting WTC & $351(36.9)$ & $410(41.7)$ & $<0.05$ \\
\hline $\begin{array}{l}\text { People falling or jumping from the } \\
\text { WTC }\end{array}$ & $305(32.2)$ & $386(39.6)$ & $<0.001$ \\
\hline Building collapsing & $584(61.4)$ & $660(67.1)$ & $<0.01$ \\
\hline $\begin{array}{l}\text { People running away from a } \\
\text { cloud or smoke }\end{array}$ & $535(56.3)$ & $645(65.7)$ & $<0.0001$ \\
\hline People injured or killed & $406(42.9)$ & $551(56.7)$ & $<0.0001$ \\
\hline \multicolumn{4}{|l|}{ Sustained any injury on $9 / 11^{\mathrm{b}}$} \\
\hline Yes & $160(16.8)$ & $247(25.1)$ & \multirow[t]{2}{*}{$<0.0001$} \\
\hline No & $792(83.2)$ & $736(74.9)$ & \\
\hline \multicolumn{4}{|l|}{ Bereavement due to $9 / 11$} \\
\hline Bereaved & $1070(29.5)$ & $777(61.9)$ & $<0.0001$ \\
\hline \multicolumn{4}{|c|}{ Worked on the pile at the WTC site } \\
\hline Yes & 439 (11.9) & $442(34.8)$ & \multirow[t]{2}{*}{$<0.0001$} \\
\hline No & $3257(88.1)$ & $829(65.2)$ & \\
\hline \multicolumn{4}{|l|}{ First day of volunteer work } \\
\hline September 11, 2001 & $162(4.8)$ & $360(29.7)$ & \multirow[t]{5}{*}{$<0.0001^{\mathrm{a}}$} \\
\hline September 12, 2001 & $196(5.8)$ & $300(24.7)$ & \\
\hline September 13-17, 2001 & $396(11.6)$ & $350(28.8)$ & \\
\hline September 18-December 31, 2001 & $1657(48.7)$ & $173(14.3)$ & \\
\hline January 1, 2002-June 30, 2002 & $995(29.2)$ & $31(2.6)$ & \\
\hline \multicolumn{4}{|l|}{$\begin{array}{l}\text { Number of days worked at any WTC } \\
\text { site }^{d}\end{array}$} \\
\hline $1-7$ & $792(46.0)$ & $524(74.1)$ & \multirow[t]{4}{*}{$<0.0001$} \\
\hline $8-30$ & $650(37.7)$ & $118(16.7)$ & \\
\hline $31-90$ & $190(11.0)$ & $39(5.5)$ & \\
\hline$>90$ & $91(5.3)$ & $26(3.7)$ & \\
\hline
\end{tabular}

a Cochran-Armitage Trend Test.

b Restricted to enrollees who were present on 9/11.

c Not mutually exclusive.

d Worked on the pile, Staten Island, or barge.

because they lived or worked nearby on the morning of 9/11. Most affiliated volunteers enrolled in the Registry were non-NYC residents, thus arriving later due to travel restrictions.

Previous studies have identified factors associated with increased risk of post-disaster depression, PTSD, and anxiety: witnessing horrific events, lack of preparation or training, sustaining an injury, personal identification or relationship with victims and losing a loved one (Brackbill, et al., 2009, Perrin, et al., 2007, Thormar, et al., 2010). Our findings indicate that lay volunteers were more likely to have experienced these factors than affiliated volunteers, thereby increasing their risk for post-disaster mental health conditions.

Lay volunteers present in lower Manhattan on 9/11 may have had more exposure to respirable particulate matter and other substances associated with asthma and other respiratory outcomes, especially those working on the pile (Brackbill, et al., 2009). Lay volunteers belonging to multiple eligibility groups were potentially subject to more 9/11-related exposures than other RRW such as dust contaminated homes or work places that have been associated with increased risk 
Table 3

Mental and physical health outcomes among World Trade Center Health Registry volunteer groups' 2006-07. $\mathrm{N}=4,974$.

\begin{tabular}{|c|c|c|c|}
\hline & Affiliated volunteers & Lay volunteers & P-value \\
\hline & $(\mathrm{n}=3.702)$ & $(\mathrm{n}=1,272)$ & \\
\hline & $\mathrm{n}(\%)$ & $\mathrm{n}(\%)$ & \\
\hline \multicolumn{4}{|c|}{ Post-9/11 mental health diagnoses } \\
\hline None & $2868(79.2)$ & $807(65.5)$ & \multirow[t]{3}{*}{$<0.0001$} \\
\hline Early $^{\text {a }}$ & $465(12.8)$ & $299(24.3)$ & \\
\hline Late $^{\mathrm{b}}$ & $209(5.8)$ & $81(6.6)$ & \\
\hline \multicolumn{4}{|c|}{ Probable posttraumatic stress disorder } \\
\hline None & $3086(86.7)$ & $791(66.0)$ & \multirow[t]{4}{*}{$<0.0001$} \\
\hline Chronic (W1+, W2+) & $192(5.4)$ & $189(15.8)$ & \\
\hline Late onset $(\mathrm{W} 1-, \mathrm{W} 2+)$ & $205(5.8)$ & $166(13.8)$ & \\
\hline Resolved $(\mathrm{W} 1+, \mathrm{W} 2-)$ & $75(2.1)$ & $53(4.4)$ & \\
\hline \multicolumn{4}{|c|}{ New or worsening lower respiratory symptoms since $9 / 11$} \\
\hline Yes & $1275(34.9)$ & $797(63.5)$ & $<0.0001$ \\
\hline \multicolumn{4}{|l|}{ Post-9/11 asthma/RADS c,d } \\
\hline None & 2946 (95.7) & $945(91.5)$ & \multirow[t]{3}{*}{$<0.0001$} \\
\hline Early ${ }^{a}$ & $64(2.1)$ & $53(5.1)$ & \\
\hline Late $^{\mathrm{b}}$ & $69(2.2)$ & $35(3.4)$ & \\
\hline
\end{tabular}

${ }^{a}$ Diagnosed between 09/11/01 and 12/31/03.

b Diagnosed between 01/01/04 and 12/31/07.

c RADS-reactive airway dysfunction syndrome.

d Limited to those with known date of diagnosis or known to have diagnosis.

for LRS and asthma/RADS (Brackbill, et al., 2009, Herbert, et al., 2006, Lin, et al., 2005).

Both volunteer groups reported unmet health care needs at W2, with the majority of whom were attempting to seek health care for a 9/11-related problem. Both groups also reported low utilization of post-9/11 medical monitoring and treatment programs. The frequency of reporting unmet health care needs was greater in lay volunteers ( $29.8 \%$ vs. $16.1 \%, p<0.0001)$. Of those reporting unmet needs, a greater proportion of lay volunteers were unable to get care for a perceived 9/11-related problem (lay $70.0 \%$ vs. affiliated $42.7 \%$ ). Less than $10 \%$ of all volunteers (8.7\%) reported receiving services from a post-9/11 medical monitoring or treatment program and utilization of programs was lower among affiliated than lay volunteers (7.0\% vs. $13.9 \%)$.

At the time of W2, awareness of these programs was low and some volunteers may have been unclear about program eligibility. The post-9/11 health care programs for RRW have strict eligibility criteria regarding duration of work at the disaster sites, which not all

Table 4.1

Multinomial odds ratios for mental health outcomes among lay volunteers compared to affiliated volunteers.

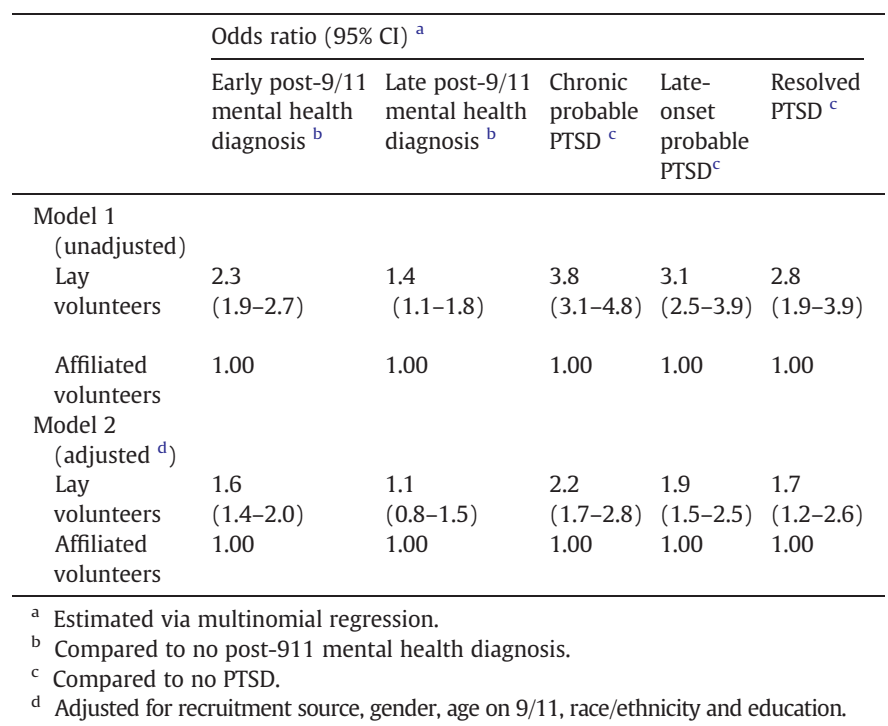

Table 42

Multinomial odds ratios for physical health outcomes among lay volunteers compared to affiliated volunteers.

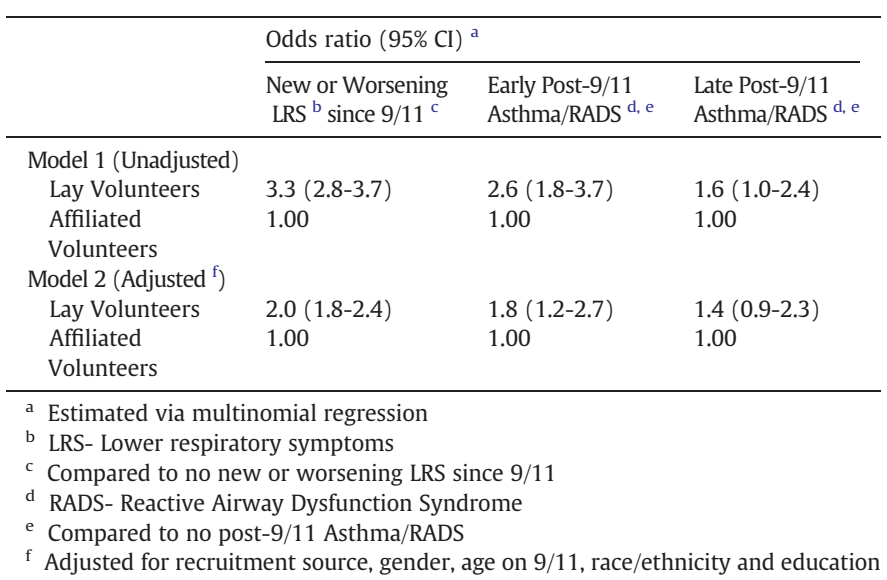

volunteers met. Many volunteers may have lacked documentation for acceptance into a program. During W2, most 9/11 medical monitoring and treatment programs were located in New York/New Jersey, while most affiliated volunteers (56.5\%) lived outside of the area. Project Liberty, NYS's primary post-9/11 crisis counseling program, provided services only to NYS residents (Donahue, et al., 2006). In 2002, due to the unique circumstances of $9 / 11$, Congress authorized \$25 million for Workers' Compensation benefits for WTC volunteers who otherwise would have been ineligible for benefits. As such, a portion of volunteers' post-9/11 medical related needs may have been met by the NYS Workers' Compensation System. As of September 2009, over 1000 WTC volunteers had received benefits (New York State Workers' Compensation Board, 2009). Enrollment for WTC-related NYS Workers' Compensation ended 09/10/10.

One study limitation is selection bias. Despite efforts to include all eligible rescue/recovery volunteers, volunteers in the Registry may not be representative of all volunteers. Self-identified enrollees were more likely to report probable PTSD, new or worsening LRS, and newly diagnosed asthma than list-identified enrollees (Brackbill, et al., 2009, Farfel, et al., 2008). However, the prevalence of both PTSD and LRS was still two-fold higher among list-identified lay volunteers compared to list-identified affiliated volunteers (data not shown). Self-reported data collected up to five to six years after the disaster may be subject to recall bias. Volunteers with greater exposure to the disaster may have been more likely to recall and connect their symptoms to the disaster than volunteers with lesser exposure. Due to the lack of detailed documentation of actual tasks performed and duration of time worked by volunteers who did not perform work on the pile, we were unable to examine the full range of activities performed by all volunteers. Finally, there is a potential misclassification of volunteer type. As previously mentioned, many lay volunteers had to join a professional organization in order to continue volunteering. It is possible that not all individuals self-identifying as affiliated volunteers had the level of pre-disaster experience and/or training ordinarily provided by those organizations. This may have resulted in a differential misclassification error, which could have led to an underestimation of the differences between volunteer groups.

\section{Conclusions}

Man-made and natural disasters often require rapid deployment of large scale rescue, recovery and cleanup efforts. Disaster relief organizations, even if well prepared, could not have responded instantaneously to a disaster of 9/11's magnitude because of logistic and travel limitations. Urgent post-disaster needs for rescue, recovery, and cleanup are 
often filled by individuals who volunteer spontaneously, and it is likely that volunteers will continue to play an integral role in these efforts, despite exposure to potential health hazards.

Protecting disaster responders should be a major public health priority. Many cities and states have extensive disaster management plans, but few are equipped for long-term health surveillance on the scale of $9 / 11$. The experience of both professional and volunteer responders to $9 / 11$ indicates a need for the provision of site-specific training, regardless of prior disaster experience, to limit exposure to specific hazards and familiarize volunteers with safe operating procedures.

When exposure to toxic substances is suspected, agencies charged with monitoring long-term health of professional responders should extend this function to volunteers. For illnesses with long latency periods, monitoring activities should follow a cohort design, by establishing and maintaining a roster containing: names, contact information, baseline health screening, tasks performed, and timing and duration of work. An example is the database of clean-up workers and volunteers created after the 2010 oil spill in the Gulf of Mexico. These activities should be followed up with regular assessments of mental and physical health and health care needs, including a mechanism for making appropriate referrals to care. Rosters of volunteers will provide an avenue for outreach and education promoting awareness of post-disaster services such as monitoring and treatment programs and Workers' Compensation benefits. Inevitably, monitoring and treatment costs will emerge as potential obstacles to maintaining such programs. The data presented in this study represent a first step in determining the magnitude of existing needs.

\section{Conflict of interest statement}

There is none to declare.

\section{Acknowledgments}

This study was supported by Cooperative Agreement 1U50/ OH009739 from the National Institute for Occupational Safety and Health (NIOSH) of the U.S. Centers for Disease Control and Prevention (CDC); Cooperative Agreement U50/ATU272750 from the Agency for Toxic Substances and Disease Registry (ATSDR) which included support from the National Center for Environmental Health (NCEH); and the New York City Department of Health and Mental Hygiene (NYC DOHMH). We would like to thank Dr. Carey Maslow, Dr. JieHui Li, and Daniel Wallingford for their technical assistance. We would like to thank the enrollees in the World Trade Center Health Registry for their participation in our surveys. We would also like to acknowledge the volunteers and rescue/recovery workers for their service on $9 / 11$ and thereafter. The views expressed in this article are those of the authors and do not necessarily represent the views of ATSDR, NIOSH, NCEH, or NYC DOHMH.

\section{References}

American Psychiatric Association, 1994. Diagnostic and statistical manual of mental disorders (4th ed., text rev.). Washington, DC: Author.

American Red Cross, 2002. September 11, 2001: Unprecedented Events, Unprecedented Response. American Red Cross.

Bills, C.B., Levy, N.A., Sharma, V., Charney, D.S., Herbert, R., Moline, J., Katz, C.L., 2008 Mental health of workers and volunteers responding to events of 9/11: review of the literature. Mt. Sinai J. Med. 75, 115-127.

Blanchard, E.B., Jones-Alexander, J., Buckley, T.C., Forneris, C.A., 1996. Psychometric properties of the PTSD checklist (PCL). Behav. Res. Ther. 34, 669-673.

Brackbill, R.M., Hadler, J.L., DiGrande, L., Ekenga, C.C., Farfel, M.R., Friedman, S., Perlman, S.E., Stellman, S.D., Walker, D.J., Wu, D., Yu, S., Thorpe, L.E., 2009. Asthma and posttraumatic stress symptoms 5 to 6 years following exposure to the World Trade Center terrorist attack. JAMA 302, 502-516.

Dobie, D.J., Kivlahan, D.R., Maynard, C., Bush, K.R., McFall, M., Epler, A.J., Bradley, K. A., 2002. Screening for post-traumatic stress disorder in female Veteran's Affairs patients: validation of the PTSD checklist. Gen. Hosp. Psychiatry 24, 367-374.

Donahue, S.A., Lanzara, C.B., Felton, C.J., Essock, S.M., Carpinello, S., 2006. Project Liberty: New York's crisis counseling program created in the aftermath of September 11, 2001. Psychiatr. Serv. 57, 1253-1258.

Farfel, M., DiGrande, L., Brackbill, R., Prann, A., Cone, J., Friedman, S., Walker, D. Pezeshki, G., Thomas, P. Galea, S., Williamson, D., Frieden, T. Thorpe, L., 2008. An overview of $9 / 11$ experiences and respiratory and mental health conditions among World Trade Center Health Registry enrollees. J. Urban Health 85, 880-909.

Herbert, R., Moline, J., Skloot, G., Metzger, K., Baron, S., Luft, B., Markowitz, S., Udasin, I., Harrison, D., Stein, D., Todd, A., Enright, P., Stellman, J.M., Landrigan, P.J., Levin, S. M., 2006. The World Trade Center disaster and the health of workers: five-year assessment of a unique medical screening program. Environ. Health Perspect. 114 1853-1858.

Koenen, K., Stellman, J.M., Stellman, S.D., Sommer, J.F., 2003. Risk factors for course of posttraumatic stress disorder among Vietnam veterans: a 14-year follow-up of American Legionnaires. J. Consult. Clin. Psychol. 71, 980-986.

Landrigan, P.J., Lioy, P.J., Thurston, G., Berkowitz, G., Chen, L.C., Chillrud, S.N., Gavett, S. H., Georgopoulos, P.G., Geyh, A.S., Levin, S., Perera, F., Rappaport, S.M., Small, C., 2004. Health and environmental consequences of the world trade center disaster. Environ. Health Perspect. 112, 731-739.

Lin, S., Reibman, J., Bowers, J.A., Hwang, S.A., 2005. Upper respiratory symptoms and other health effects among residents living near the World Trade Center site after September 11, 2001. Am. J. Epidemiol. 162, 499-507.

Lorber, M., Gibb, H., Grant, L., Pinto, J., Pleil, J., Cleverly, D., 2007. Assessment of inhalation exposures and potential health risks to the general population that resulted from the collapse of the World Trade Center towers. Risk Anal. 27, 1203-1221.

Murphy, J., Brackbill, R.M., Thalji, L., Dolan, M., Pulliam, P., Walker, D.J., 2007. Measuring and maximizing coverage in the World Trade Center Health Registry. Stat. Med. 26, 1688-1701.

New York State Workers' Compensation Board, 2009. World Trade Center Cases in the New York Workers' Compensation System. New York State.

Perrin, M.A., DiGrande, L., Wheeler, K., Thorpe, L., Farfel, M., Brackbill, R., 2007. Differences in PTSD prevalence and associated risk factors among World Trade Center disaster rescue and recovery workers. Am. J. Psychiatry 164, 1385-1394.

Ruggiero, K.J., Ben, K.D., Scotti, J.R., et al., 2003. Psychometric properties of the PTSD checklist-civilian version. J. Trauma. Stress 16, 495-502.

SAS, 2005. Statistical Analysis System, Cary, NC.

Steffen, S.L., Fothergill, A., 2009. 9/11 volunteerism: a pathway to personal healing and community engagement. Soc. Sci. J. 46, 29-46.

Thormar, S.B., Gersons, B.P., Juen, B., Marschang, A., Djakababa, M.N., Olff, M., 2010. The mental health impact of volunteering in a disaster setting: a review. J. Nerv. Ment. Dis. $198,529-538$.

Tierney, K., Lindell, M.K., Perry, R.W., 2001. Facing the unexpected:disaster preparedness and response in the United States. Joseph Henry Press, Washington, DC. 